\title{
TESTING RADIO SIGNAL RANGE OF SELECTED COMPONENTS
}

The radio signals range of selected wireless components of security systems is defined by the area within which components can communicate properly. In practice, the range of communication between components is often insufficiently taken into account, which results in the system malfunction. There are cases where the radio signal range of wireless components was inadequate due to use in an environment constructed from non-transmitting materials.

The installation of wireless systems requires the implementation of a testing methodology of radio-communication range and its continuous improvement. Currently, the procedures within EN 50 131-5-3 and EN 300 220-1 standards can be used to test the wireless components, but they do not target the range between wireless components.

Dependability and functionality are the main attributes of electrical security systems and need to be verified by testing the range of wireless components.

Keywords: alarm systems, signal range, wireless, communication, motion detector

\section{Introduction}

Security systems are nowadays a common inseparable standard of operations, facilities, family houses and other utilities. As technology evolves, the classic Intruder alarm systems (IAS) wired components are no longer adequate and need to be complemented by the wireless ones. Those have become synonymous with low cost, time saving, easy implementation, easy maintenance and flexibility. They are suitable for spaces where classic cabling (already occupied premises, historical buildings, etc.) cannot be conducted.

However, wireless communication between components also has its limits. Those are the specific limits of the signal range, which affect the dependability of the entire security system. It is thus important to define the problem of the signal range of selected wireless components of the security systems; to find out to what extent the range of the communication signal is influenced by the environment; to examine whether the range can be determined in general by using a specific parameter. This issue is important for effectively managing the selection and placement of selected wireless components when designing and implementing wireless IAS [1].

The $433 \mathrm{MHz}$ and $868 \mathrm{MHz}$ bands have different range, functionality and dependability parameters that can be affected by compliance with the wireless component assembly recommendations. The range is also affected by the attenuation properties of materials that are different for each frequency and can be measured by the spectral analyzer. For the range calculation, a component parameter can also be used: the radiated signal strength that can be obtained by measuring in a non-impact chamber [1], [2]. This work describes testing for which Jablotron wireless components were used. The testing took place at the premises of dormitories of the University of Zilina's and at the CEBIA-Tech center in Zlin.

\subsection{Wireless radio communication of security system components}

Wireless communication works on the principle of telegraph, that is, the components communicate with each other through short messages at a certain time on frequencies belonging to ultrashort waves [2]. The messages are encoded with the information about the state of the monitored object.

In practice, the electromagnetic field intensity (E_x) parameter is used to calculate the range. Its value is determined by measuring, in a remote field where the capacitance and inductive coupling is not applied, the energy transmitted by electromagnetic

\footnotetext{
* ${ }^{1}$ Andrej Velas, ${ }^{1}$ Tomas Lovecek, ${ }^{2}$ Jan Valouch, ${ }^{3}$ Jacek Dworzecki, ${ }^{1}$ Eva Vnencakova

${ }^{1}$ Department of Security Management, Faculty of Security Engineering, University of Zilina, Slovakia

${ }^{2}$ Department of Security Engineering, Faculty of Applied Informatics Tomas Bata, University in Zlin, Czech Republic

${ }^{3}$ Police Academy in Szczytno, Poland

Email: andrej.velas@fbi.uniza.sk
} 
Table 1 Technical Parameters of the JA-60 Series Components, [5], [6]

\begin{tabular}{|c|c|}
\hline \multicolumn{2}{|c|}{ Technical Parameters - UC- 260 Annunciator } \\
\hline Working frequency & $433.9 \mathrm{MHz}$ \\
\hline Way of communication & One-way communication \\
\hline \multicolumn{2}{|c|}{ Technical Parameters - JA- 60P Detector } \\
\hline Range & $100 \mathrm{~m}$ to direct visibility \\
\hline Working frequency & $433.9 \mathrm{MHz}$ \\
\hline Way of communication & One-way communication \\
\hline \multicolumn{2}{|c|}{ Technical Parameters - JA- RC11 Remote Control } \\
\hline Range & $30 \mathrm{~m}$ to direct visibility \\
\hline Working frequency & $433.9 \mathrm{MHz}$ \\
\hline Way of communication & One-way communication \\
\hline
\end{tabular}

Table 2 Technical Parameters of the JA- 100 Series Components, [5], [6]

\begin{tabular}{|c|c|}
\hline \multicolumn{2}{|c|}{ Technical Parameters - Module JA- 110R } \\
\hline Working frequency & $868.1 \mathrm{MHz}$ \\
\hline Way of communication & Two-way communication \\
\hline \multicolumn{2}{|c|}{ Technical Parameters - Detector JA- 160PC } \\
\hline Range & $300 \mathrm{~m}$ to direct visibility \\
\hline Working frequency & 868.1 MHz \\
\hline Way of communication & Two-way communication \\
\hline \multicolumn{2}{|c|}{ Technical Parameters - Detector JA-151M } \\
\hline Range & $200 \mathrm{~m}$ to direct visibility \\
\hline Working frequency & $868.1 \mathrm{MHz}$ \\
\hline Way of communication & Two-way communication \\
\hline \multicolumn{2}{|c|}{ Technical Parameters - Detector JA- 180B } \\
\hline Range & $100 \mathrm{~m}$ to direct visibility \\
\hline Working frequency & 868.1 MHz \\
\hline Way of communication & One-way communication \\
\hline \multicolumn{2}{|c|}{ Technical Parameters - Remote Control JA- 154J } \\
\hline Range & $30 \mathrm{~m}$ to direct visibility \\
\hline Working frequency & $868.1 \mathrm{MHz}$ \\
\hline Way of communication & Two-way communication \\
\hline
\end{tabular}

waves, and the ratio between the components of the E - electric field strength and the $\mathrm{H}$ - magnetic field strength is given by the impedance of the wave saturated environment.

For the electric field strength, the following applies:

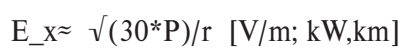

where $P$ is the power of the tested device and $r$ is the distance of the tested device from the measuring device. Measurement takes place either in the open space or in the non-impact chamber, the properties of which are defined in the relevant standards. The uncertainty of electromagnetic radiation intensity measurement can be $\pm 4 \mathrm{~dB}[3]$.
As soon as we know the effective radiated power, we can already calculate the intensity of the electric component of the electromagnetic field at a particular distance from the transmitting antenna [4].

\section{Testing methods}

Components of the Jablotron company operating at $433 \mathrm{MHz}$ and $868 \mathrm{MHz}$ with declared ranges of 30,100 and 300 meters were tested. 


\section{kOMNlkocie}

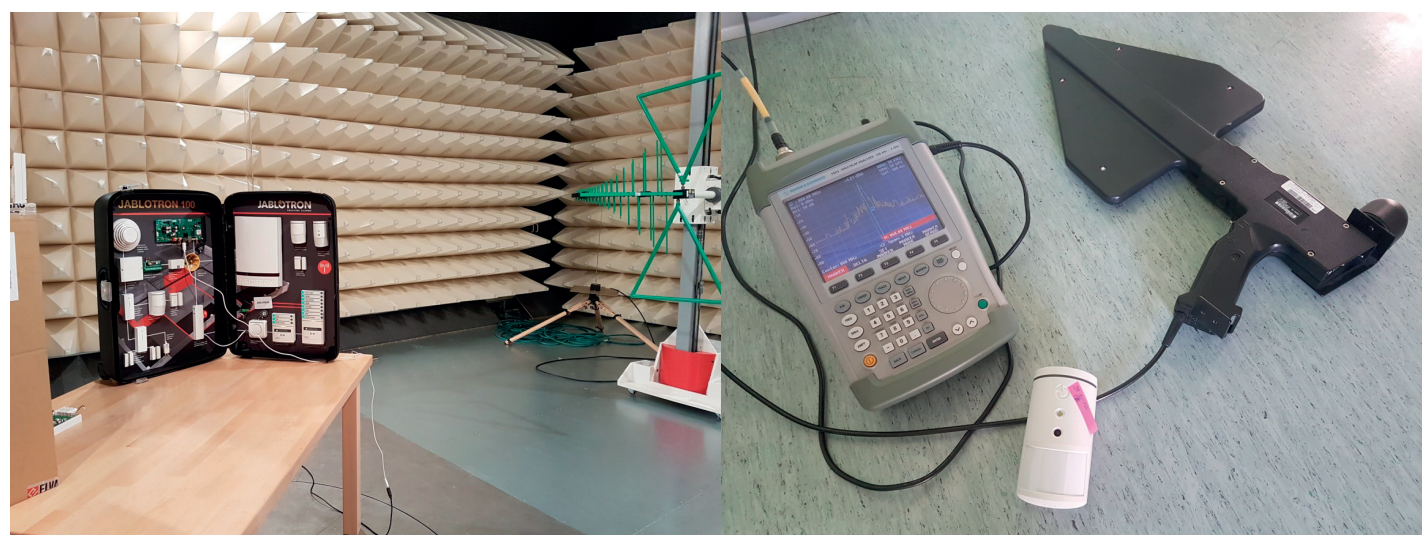

Figure 1 The Franconia non-reflecting chamber and the spectrum analyzer and the antenna during testing

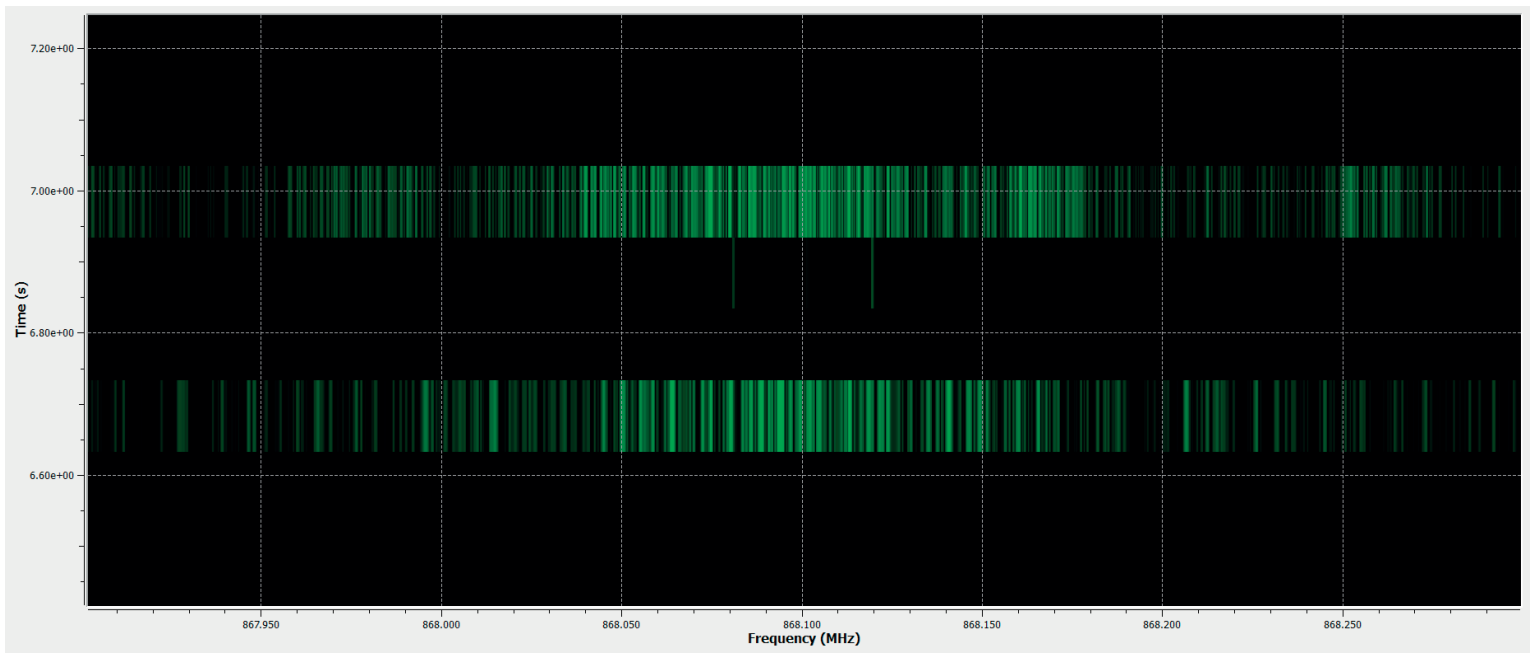

Figure 2 Frequency spectrum detail when transmitting an alarm message from the periphery

- JA- 60 series (UC-260 Wireless Acoustic Annunciator, JA60P Wireless PIR Detector, JA- RC11 Remote Control), see Table 1.

- JA- 100 series (JA- 160PC wireless PIR video camera motion detector, mini JA- $151 \mathrm{M}$ wireless magnetic door opener, JA- 180B wireless glass-break detector and JA- 154J two-way remote control, see Table 2.

Besides the tested components, the following devices for testing were used, as well:

- The Franconia non-reflecting chamber - simulates test conditions in the open space, where the signal is not reflected but absorbed. Together with the R\&S EMC 32 measuring system it is used for measuring antennas and EMC, Figure 1.

- FSH3 spectrum analyzer with antenna - used to measure signal strength in terrain.

- EMC32 software ensures complete control and remote control of instrumentation in a non-impact chamber.

- USRP N210 - used to collect and analyze wireless signals [7].
The sequential steps of testing selected components of the 60 and 100 series were as follows:

- Radio communication observation,

- Measurement of radio signal strength,

- Measurement of attenuation size,

- Practical range testing.

\subsection{Radio communication observation}

The measurement was performed in a non-impact chamber. At 4 meters distance from the component, the measuring antenna was located at the same height as the tested component. During the measurement, the antenna was polarized and triggered an alarm. Through the USRP N210, the communication of peripherals with the control panel was monitored. With this observation, images of the monitoring and alarm message were received as well as information about the way of communication. Figure 2 shows an example of the PIR JA- 60. 


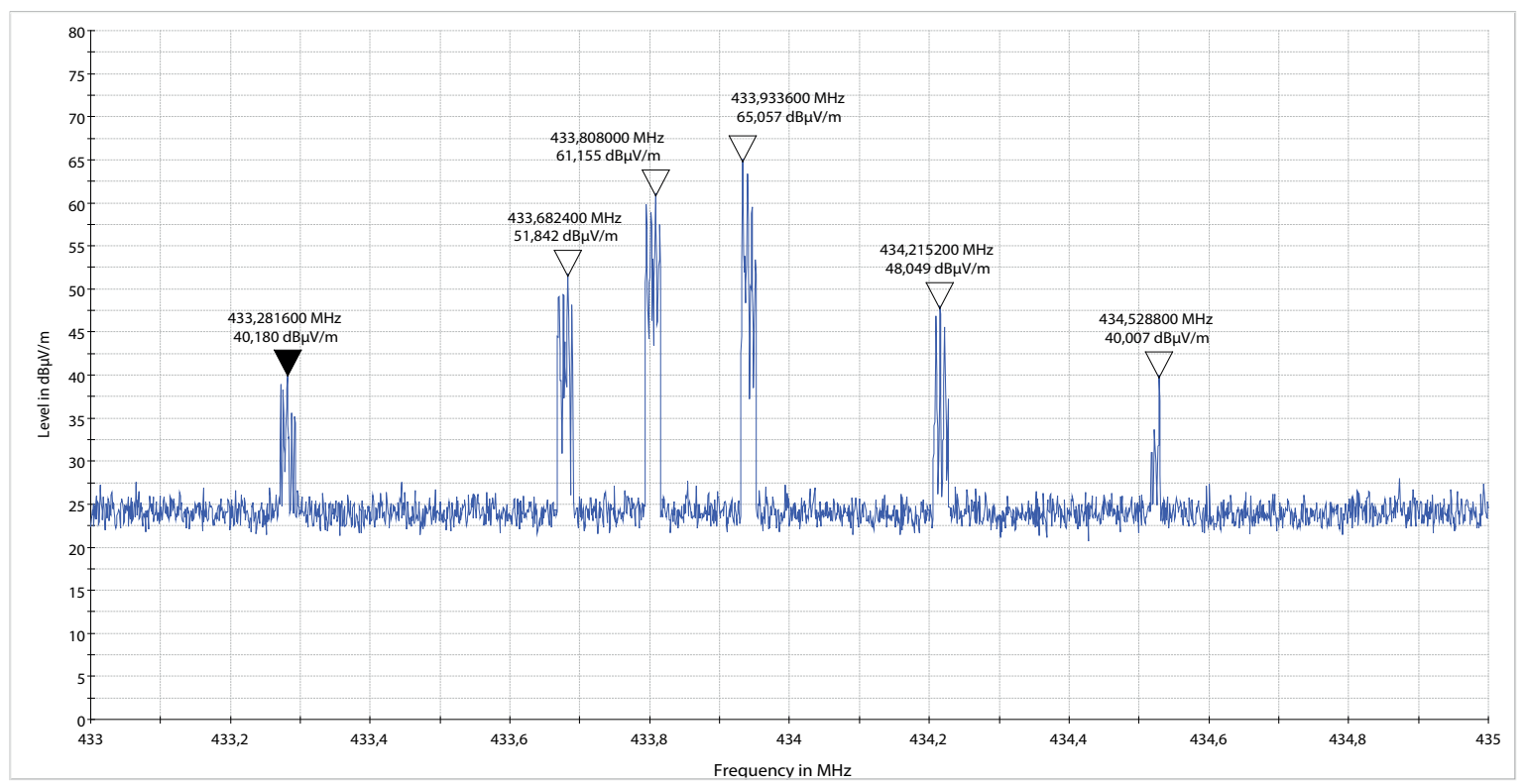

Figure 3 JA- 60P signal emission spectrum in the EMC32 program

Table 3 Table of parameters for calculating effective radiated power

\begin{tabular}{|c|c|c|c|c|c|c|}
\hline \multirow[b]{2}{*}{ Component } & \multicolumn{2}{|c|}{ Electromagnetic intensity $(\mathrm{dB} \mu \mathrm{V} / \mathrm{m})$} & \multirow[b]{2}{*}{$\begin{array}{l}\text { Frequency } \\
\quad(\mathrm{MHz})\end{array}$} & \multirow[b]{2}{*}{$\begin{array}{c}\text { Distance } \\
(\mathrm{MZ}-\mathrm{TZ}(\mathrm{m})\end{array}$} & \multirow[b]{2}{*}{$\begin{array}{c}\text { Intensity }(\mathrm{dB} \mu \mathrm{V} / \\
\mathrm{m}) \rightarrow(\mathrm{V} / \mathrm{m})\end{array}$} & \multirow[b]{2}{*}{$\begin{array}{l}\text { Component } \\
\text { power }(\mathrm{mW})\end{array}$} \\
\hline & $\begin{array}{l}\text { Horizontally } \\
\text { rotated antenna }\end{array}$ & $\begin{array}{c}\text { Vertically rotated } \\
\text { antenna }\end{array}$ & & & & \\
\hline JA- 60P & 45.851 & 65.057 & 433.8 & 4 & 0.00179 & 0.00170883 \\
\hline JA- RC11 & 51.606 & 77.74 & 433.94 & 4 & 0.007709 & 0.03169558 \\
\hline JA- $160 \mathrm{PC}$ & 80.497 & 101.226 & 868.09 & 4 & 0.1151596 & 7.07291971 \\
\hline JA- $151 \mathrm{M}$ & 94.756 & 99.657 & 868.129 & 4 & 0.0963274 & 4.94878661 \\
\hline JA- 180B & 84.574 & 100.465 & 868.089 & 4 & 0.1054994 & 5.93606609 \\
\hline JA- $154 \mathrm{~J}$ & 81.951 & 90.163 & 868.112 & 4 & 0.0322218 & 0.55373086 \\
\hline
\end{tabular}

\subsection{Measurement of radio signal strength}

The following intensity measurement was completely controlled by the EMC32 program according to the normative procedure for measuring the radiated signal in the non-impact chamber [8], [9]. The program, using a measuring antenna with $4 \mathrm{~m}$ distance from the test component, scanned the RF bands according to the set parameters and displayed the resulting spectrum of radiated signals on the screen, see Table 3 . The resultant spectrum with the values was used to calculate additional parameters. Figure 3 shows the signal emission spectrum from the JA- 60P PIR detector.

\subsection{Attenuation measurement}

Measurements of the environment attenuation were carried out, as well. There were either a door or a window, a ceiling, or a wall between the spectral analyzer antenna and the component.
The measurement was performed at the height of $1.5 \mathrm{~m}$ by directing the antenna directly to the wireless component transmitting alarm messages. One of the above-mentioned environments was between the antenna and the component. After setting the parameters, the spectral analyzer shows the frequency spectrum with the measured values, Figure 4 and Table 4.

\subsection{Practical Range Testing}

After the previous measurements, the practical testing was performed. In that measurement, the two methods were used, namely the walk-through tests and a simple function test. The component was placed at a height of $2 \mathrm{~m}$ on a non-conductive stand and in a position that most closely matches normal use. Then, the distance to the PBX, using a laser meter, was measured at the border points.

In Figure 5 are presented the measured ranges of components with an operating frequency of $433 \mathrm{MHz}$. The control panel 


\section{kam NikCle}
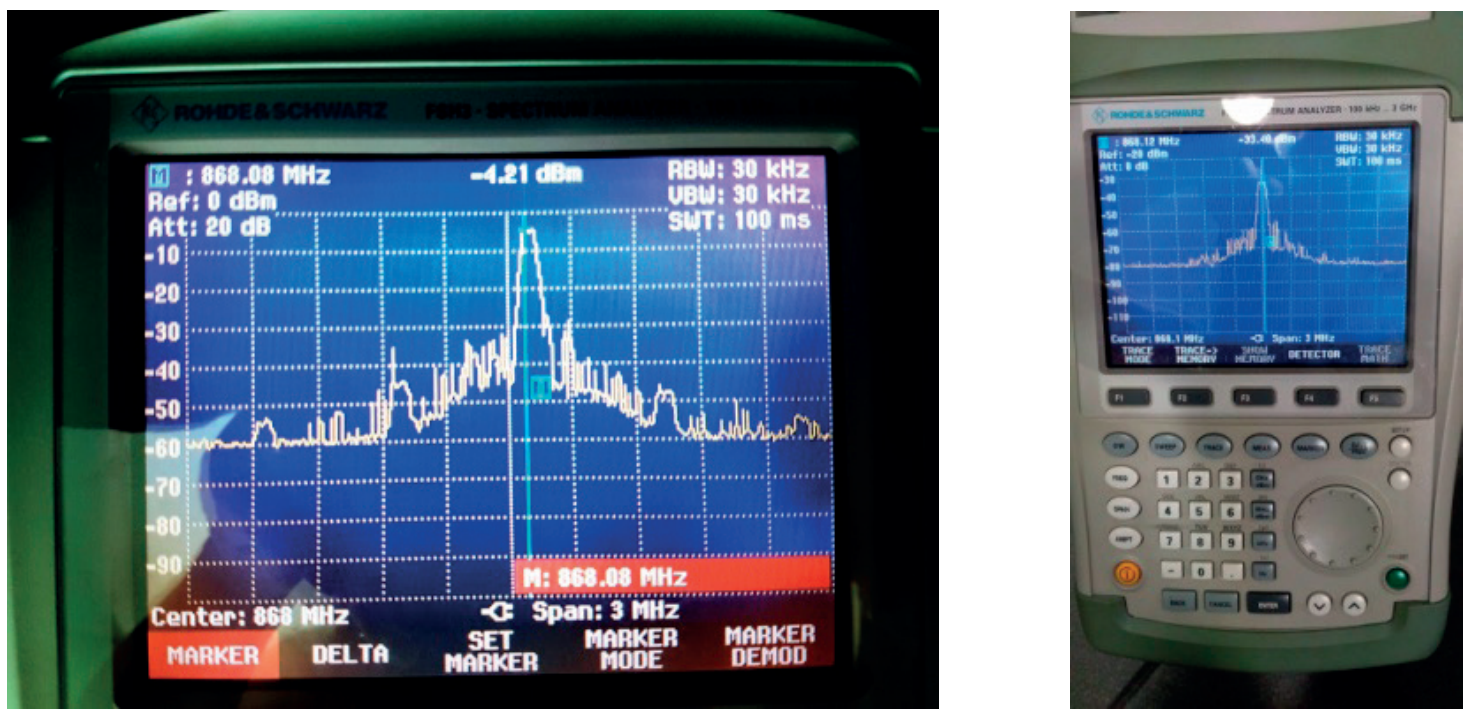

Figure 4 Demonstration of the measured value of the environment attenuation

Table 4 The magnitude of the signal attenuation in the environment at $868.1 \mathrm{MHz}$

\begin{tabular}{cc}
\hline Environment & Attenuation $(\mathrm{dB})$ \\
\hline Direct visibility $(1 \mathrm{~m})$, & 4 \\
Window & 4 \\
Door (wood $-0.035 \mathrm{~m})$ & 11 \\
One wall (non-load bearing $-0.1 \mathrm{~m}$ ) & 19 \\
Two walls (load bearing - $0.2 \mathrm{~m}$ and non-load bearing $0.1 \mathrm{~m})$ & 28 \\
Ceiling (reinforced concrete slab $-0.25 \mathrm{~m}$ ) & 34 \\
\hline
\end{tabular}

Table 5 Comparing parameters of selected components

\begin{tabular}{ccccccc}
\hline & JA- 60P & JA- RC11 & JA- 160PC & JA- 151M & JA- 180B & JA- 154J \\
\hline Declared range $(\mathrm{m})$ & 100 & 30 & 300 & 200 & 100 & 30 \\
Signal intensity $(\mathrm{dB} \mu \mathrm{V} / \mathrm{m})$ & 65.1 & 77.7 & 101.2 & 99.7 & 90.1 & 5.9361 \\
Power $(\mathrm{mW})$ & 0.0017 & 0.0317 & 7.0729 & 4.9488 & 40.5537 & 46 \\
Measured range $(\mathrm{m})$ & 30 & 19 & 54 & 43 & 37 \\
\hline
\end{tabular}

was located in the center of the building. The range of the communication signal did not exceed the boundary of the building.

Diagram in Figure 6 shows the reach of components with a working frequency of $868 \mathrm{MHz}$. The control panel was also placed in the center of the building. The ranges have significantly exceeded the boundaries of the building and are only approximate.

\section{Results}

The results of the measurement and testing are shown in the following tables and charts. First, in Table 5 are compared all the tested components with respect to the parameters that were looked at. The declared range with the measured one was compared. The actual measured values were, in almost all the cases, clearly lower than the declared range.

Another chart (Figure 7) compares the frequencies of $433 \mathrm{MHz}$ (JA- RC11) and $868 \mathrm{MHz}$ (JA- 154J). The given frequencies represent remote controls with the same declared range. Components at $868 \mathrm{MHz}$ have a larger range [10], [11]. The magnitude of the range in this case could have been influenced by the fact that the $868 \mathrm{MHz}$ band is less disturbed and thus the signal quality is better [12]

When comparing the results, a case was discovered when the JA- 180B component with a smaller declared range had a higher measuring range than the JA- $151 \mathrm{M}$, Figure 8 . Since components work at the same operating frequency, have the same antennas and have the same test conditions during the testing, the conclusion was reached that power has a significant impact 
ground floor

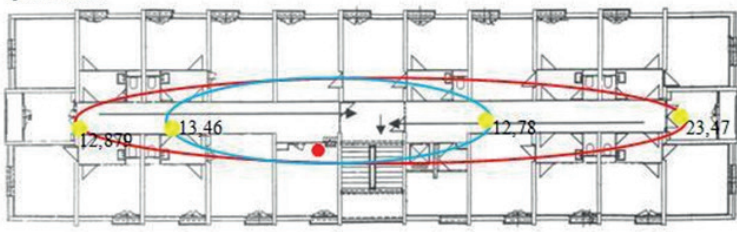

1st floor

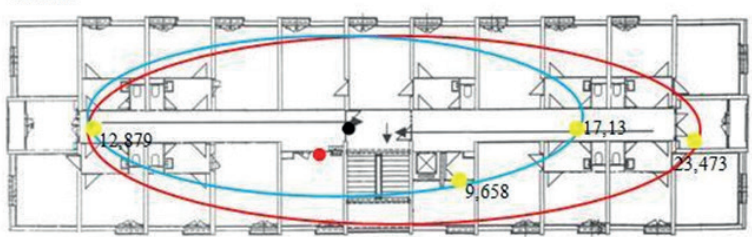

2nd floo

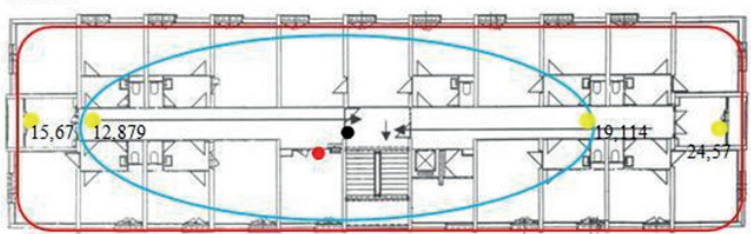

3rd floor

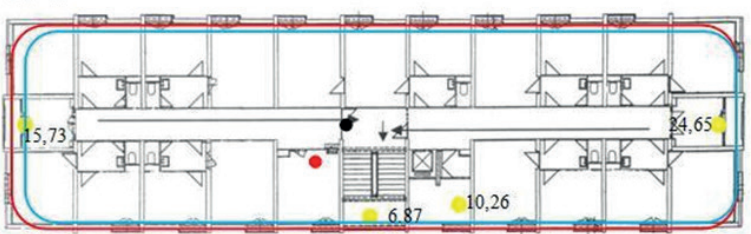

4th floor

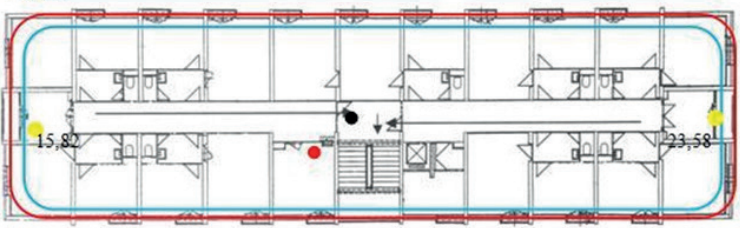

5 th floor
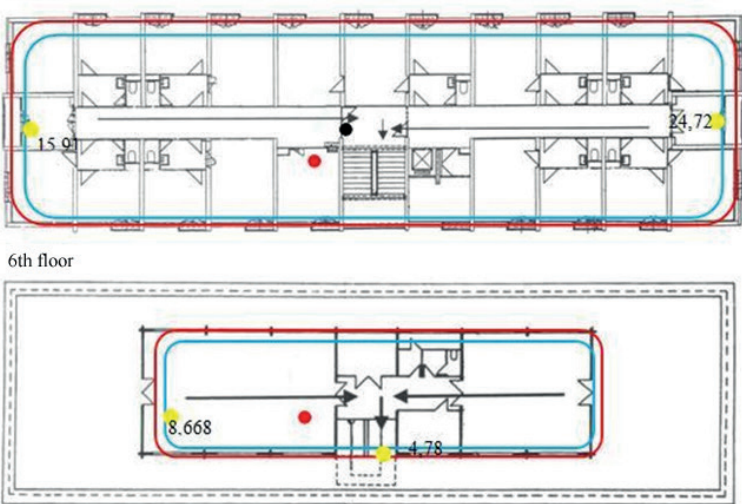

side view

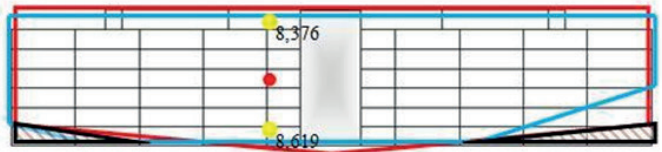

Figure 5 Sketches of the signal range for JA- 60P (marked by the black dot) and JA-RC11 (marked by the red dot). They were located in the center of the building on the $3 r d$ floor

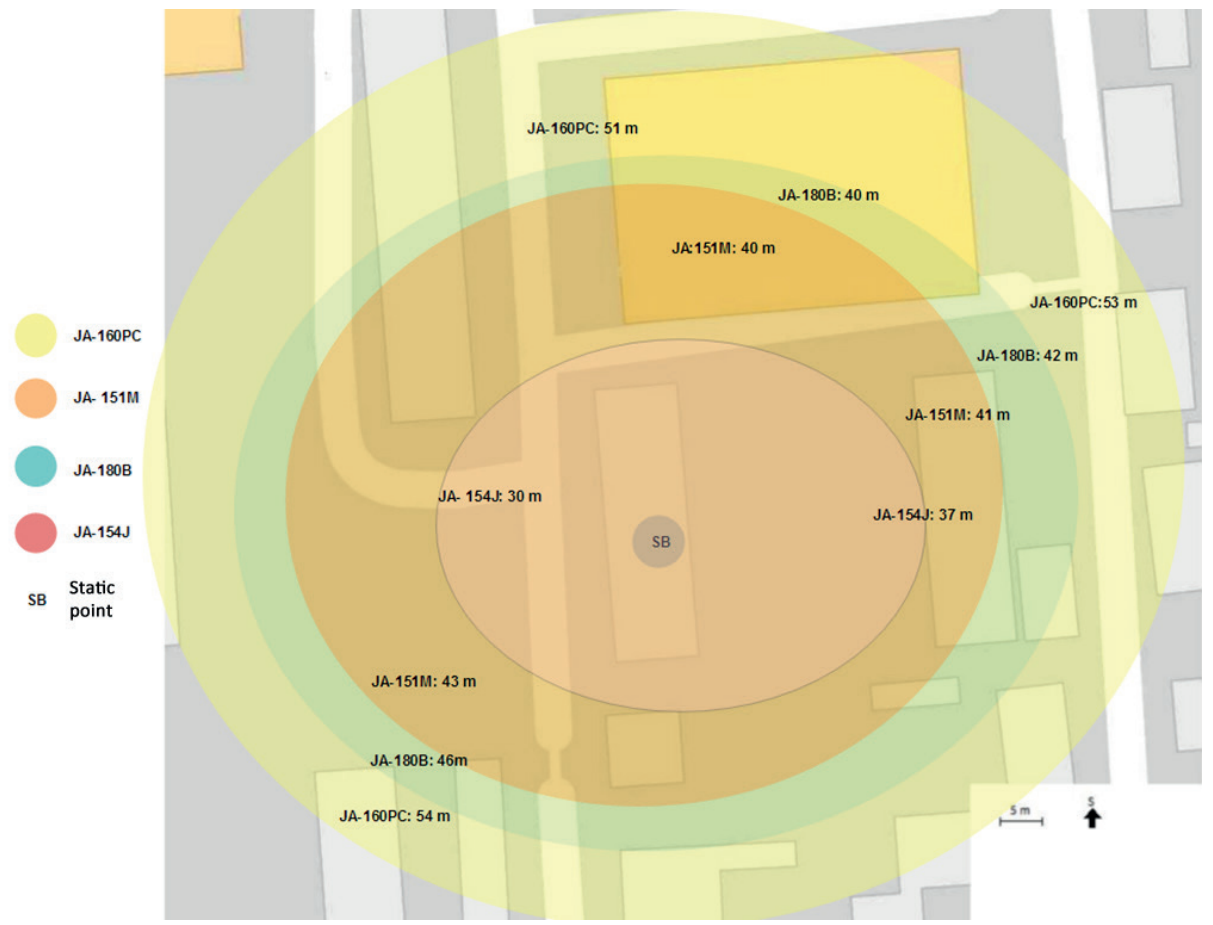

Figure 6 Sketches of the signal range of JA-160PC, JA- 51M, JA-180B and JA- $154 \mathrm{~J}$ 


\section{KOMNIKOCle}

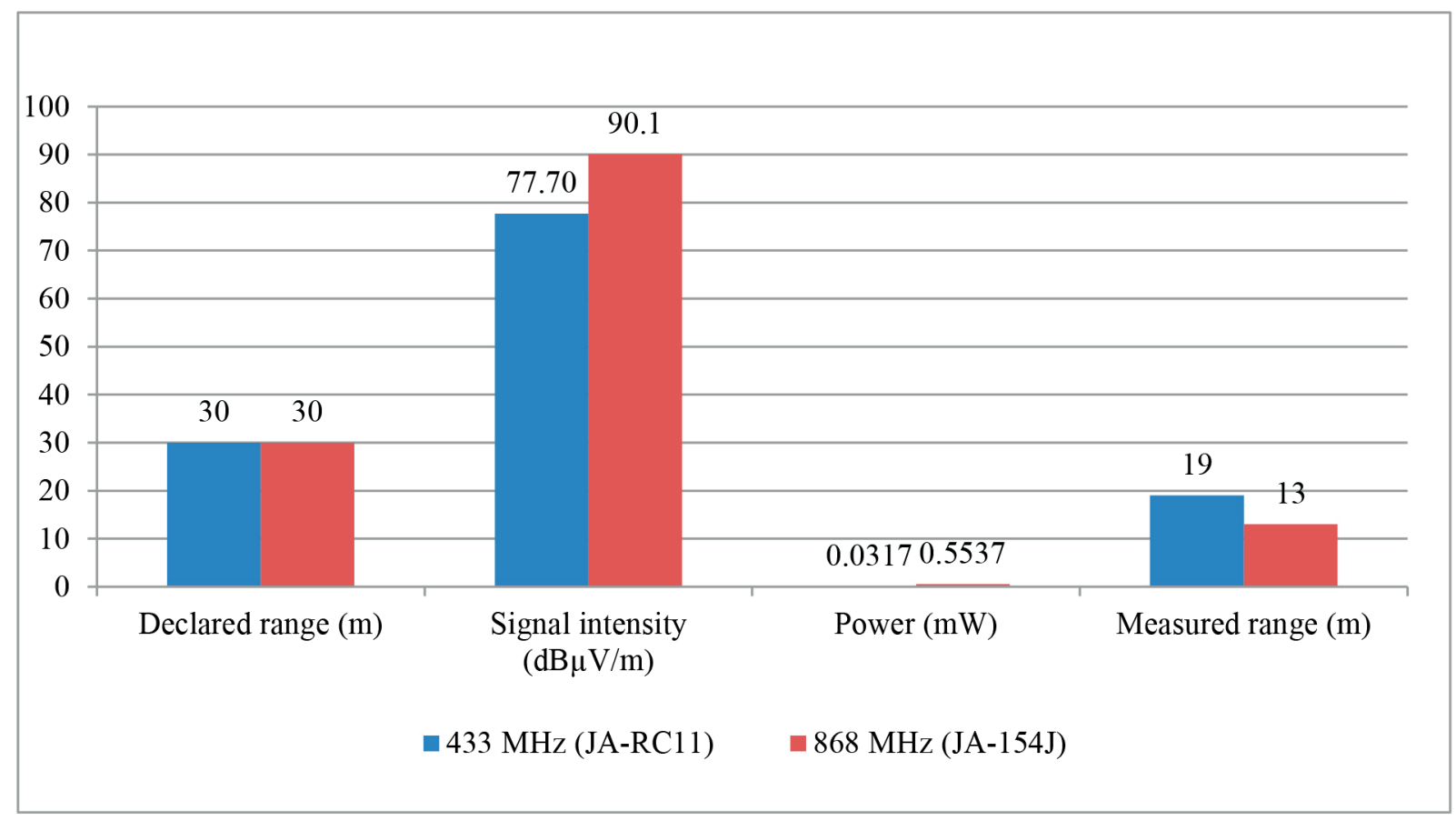

Figure 7 Comparison chart for JA- 60 and JA- 100 series components

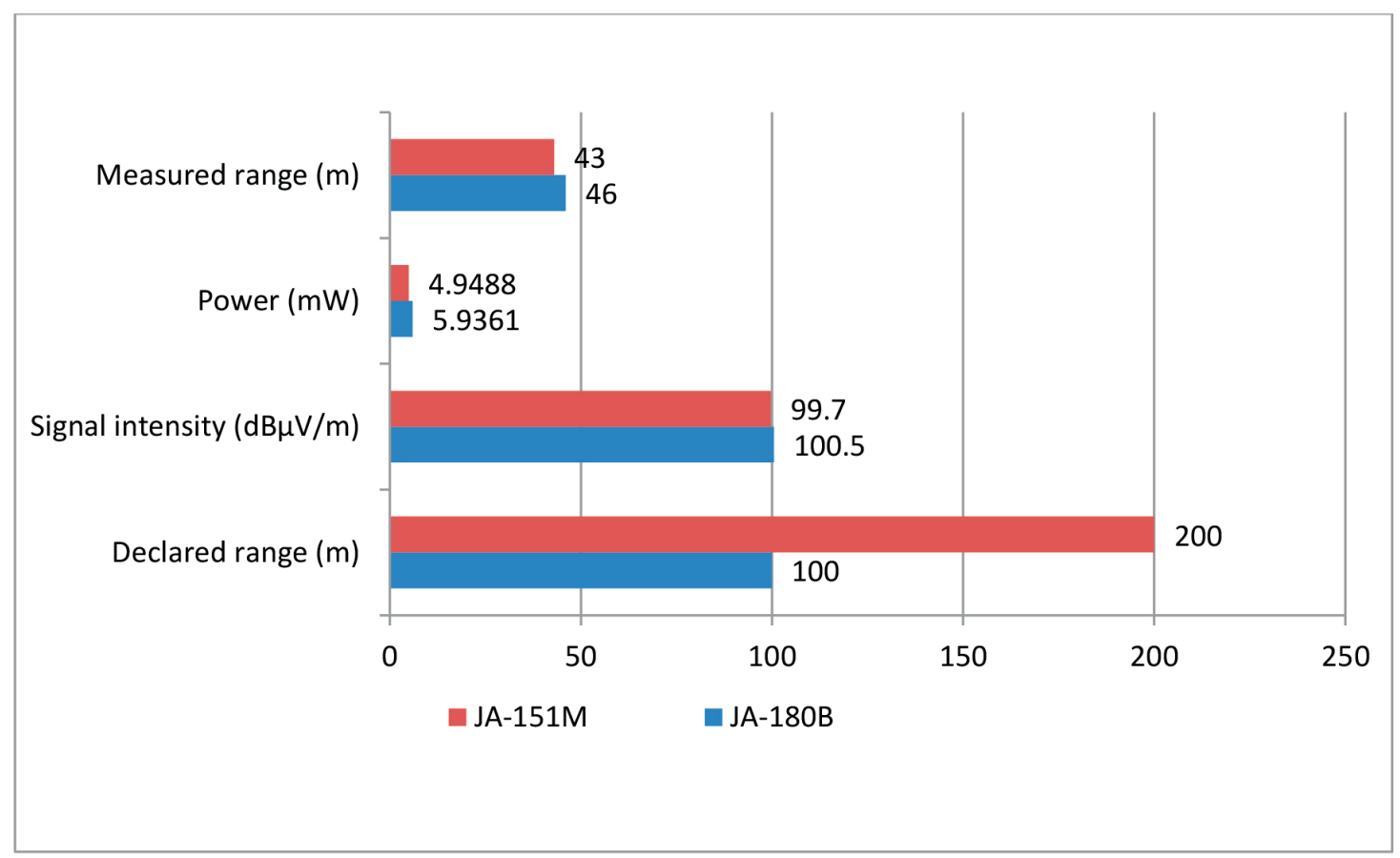

Figure 8 Graph showing power impact on range

on range. From this finding, it can be stated that the determined declared range may be incorrectly determined because there is no normative way of measuring the range.

The magnitude of the environment attenuation impact was impossible to predict or calculate in advance. The intensity of the signal was affected by the environment so much that a difference of up to $27 \mathrm{~m}$ occurred between the different lengths of the JA160PC component transmission paths. At $868 \mathrm{MHz}$, the signal has a low permeability through the materials, so it is assumed that it was reflected back to space and spread out of the window. While 


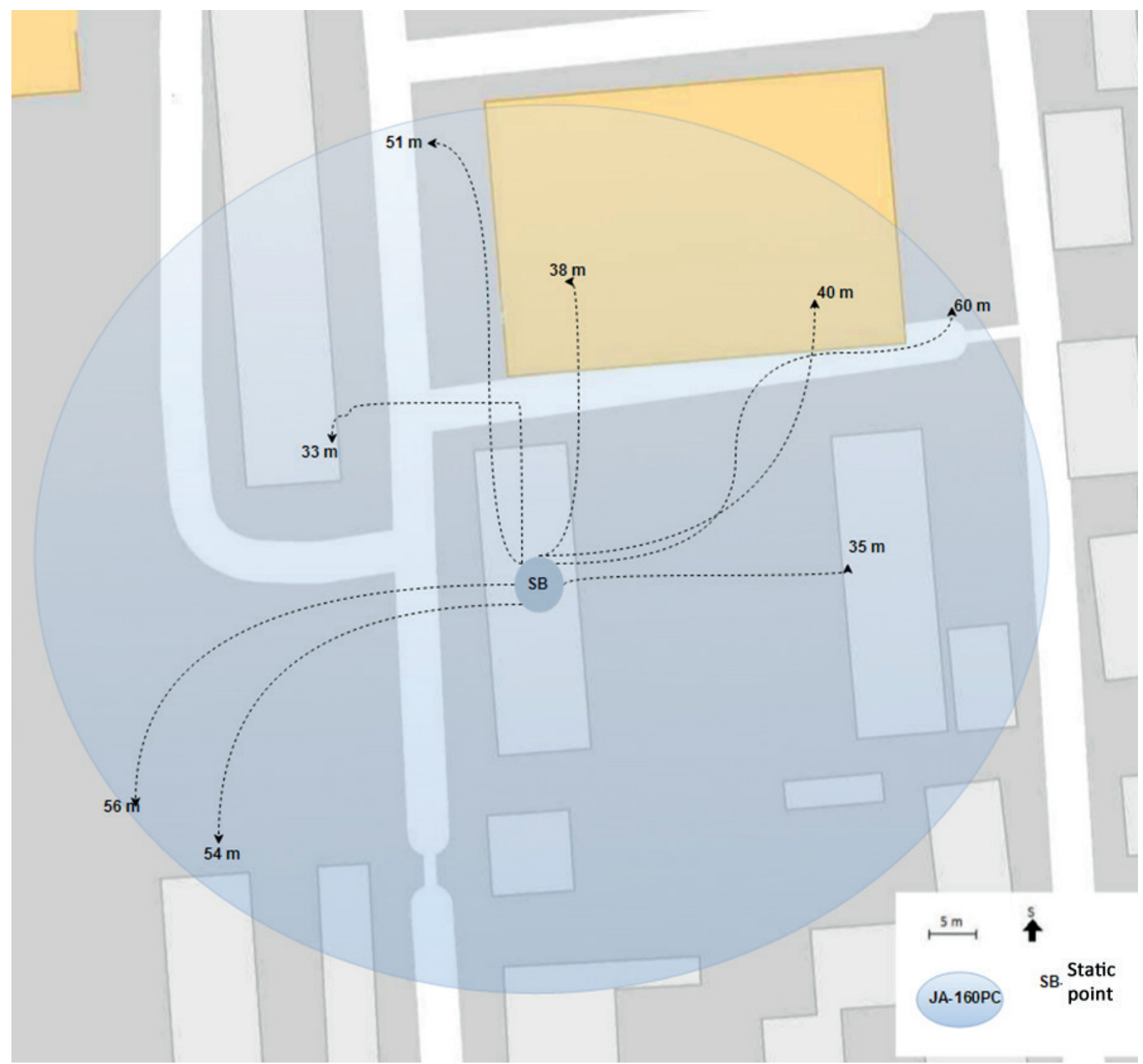

Figure 9 Outline of JA-160PC signal transmission routes from periphery

there was a range of 60 meters in the open space, it was only 33 meters inside buildings, Figure 9.

\section{Discussion}

* The problem of radio communication range cannot be calculated precisely and should therefore be verified at the installation site. In addition, the attenuation of typical environments, such as the corridor, the door and the walls, cannot be estimated beforehand either. The attenuation of the environment cannot be generalized, calculated or solidly considered.
* The $433 \mathrm{MHz}$ frequency range is much smaller, which was confirmed during the 6 -storey building test.

* The $868 \mathrm{MHz}$ frequency is less disturbed and more convenient as a working environment for security systems. The range of the $868 \mathrm{MHz}$ frequency band is much larger, with a range of 33 to 60 meters outside the building when placed in the center of the 6-storey building. It was, however, very influenced by reflections from objects and the environment.

\subsection{Options for use}

In the case of a larger object or an object of less penetrable material without windows, it is advisable to use the JA- 150R 


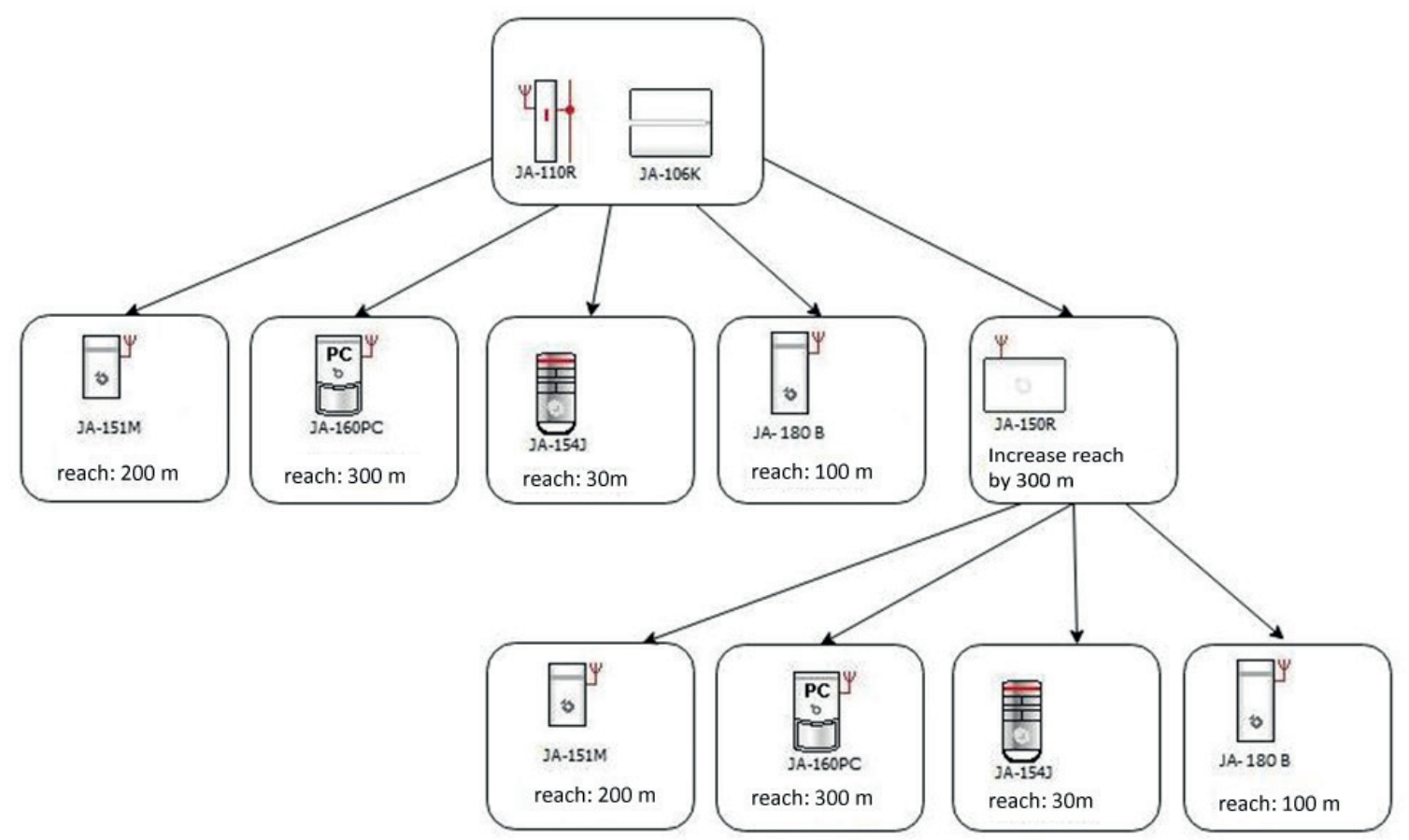

Figure 10 Typology of a wireless system to increase reach

signal repeater, which extends the range up to an additional $300 \mathrm{~m}$, Figure 10.

\subsection{Conclusions}

In this area, it is necessary to introduce the normative conditions and layout of the test facility and the testing procedure of the declared range in order to avoid errors as for instance the JA- 151M and JA- 180B components.

On-site testing should be performed in the way that the tested component is not attenuated and should therefore be placed on a stand that does not have attenuating properties. It was found that even the declared impacts are not determined correctly due to which this testing is not subject to any norm. Different test site spacing and test conditions can cause enormous differences in the calculated range under these conditions.
The range tests should always be carried out on the same site (same conditions and arrangement) and under comparable weather conditions. The real range within the limits of direct visibility in the open space should be measured on the $\mathrm{x}$ samples. From the measured values it is necessary to calculate the average values and then declare them. At the same time, it is necessary to state, in the technical parameters, that the actual range is lower in the built-up conditions [13], [14].

The found pros and cons of wireless IASs have been evaluated in the following points:

- The IAS range, installation flexibility, installation speed and great variety of wireless components to choose from, are considered as its benefits.

- As a downsides of such a system, are seen a high degree of environmental impact, the necessity to verify suitability of the component location on site, the inconsistency of the declared range with the real one, and insufficient protection against the loss of signal with the wireless periphery.

\section{References}

[1] LOVECEK, T., VELAS, A., KAMPOVA, K., MARIS, L., MOZER, V.: Cumulative Probability of Detecting an Intruder by Alarm Systems. Proceedings of the 47th IEEE Annual International Carnahan Conference on Security Technology (ICCST 2013), Colombia, 1-5, 2013.

[2] VELAS, A.: Intruder Alarm Systems. University of Zilina, Zilina, p.104, 2010.

[3] HOFREITER, L., MARIS, L., LUKAC, L., KISTER, L., GRZYWNA, Z.: New Approaches to the Analysis of the Security Environment and Their Importance for Security Management. Communications - Scientific Letters of the University of Zilina, 17(1), 99-104, 2015. 
[4] POSPISILIK, M.: Measurement of Disturbing Signals (EMI) Pre-Certification. UTB, Zlin, p. 62, 2015.

[5] SVACINA, J.: Electromagnetic Compatibility: Principles and Notes. 1. Technical University, Brno, p. 156, 2001.

[6] Electronic Control and Automation Technology [online]. Jablotron Slovakia, 2008. Available: http://www.jablotron.sk.

[7] System JABLOTRON 100 [online]. Jablotron Slovakia, 2014. Available: http://www.jablotron.sk.

[8] Electromagnetic Compatibility Measuring Instruments at Tomas Bata University in Zlin [online]. UTB, Zlin, 2015. Available: http://www.utb.cz/fai/struktura/pristroje-pro-mereni-elektromagneticke-kompatibility.

[9] General Authorization no. VPR-10/2014 for the Use of Frequencies for the Operation of Non-Specified SRD Broadcast Radio Transmitters.

[10] General Authorization no. VPR-11/2014 for the Use of Frequencies in the Frequency Band 868.6 MHz - 869.700 MHz for the Operation of Short-Range Radio Equipment in the Category of High-Reliability Low Duty Cycle Equipment.

[11] NAGY, P.: Security Systems: Control and Indicating Equipment of IAS. Faculty of Electrical Engineering, University of Zilina, Zilina, p. 26, 2005.

[12] Signal Distribution and Radio Systems Installation [online]. Eldes, 2014. Available: http://bezpecnadomacnost.sk/files/ Instalacia_bezdrotovych_systemov.pdf.

[13] SLANAR, V.: Wireless Component Communication, 2017. E-mail from viktor.slanar@jablotron.cz to vnencakova.e@gmail.com.

[14] ZAGORECKI, A. T., JOHnSON, D. E. A., RISTVEJ, J.: Data Mining and Machine Learning in the Context of Disaster and Crisis Management. International Journal of Emergency Management, 9(4), 351-365, 2013. DOI: 10.1504/IJEM.2013.059879 